九州大学学術情報リポジトリ

Kyushu University Institutional Repository

\title{
A Preliminary Investigation into Dynamics of Lotka-Volterra Equation
}

Shimojo, Masataka

Laboratory of Animal Feed Science, Division of Animal Science, Department of Animal and Marine Bioresource Sciences, Faculty of Agriculture, Kyushu University

Shao, Tao

Department of Grassland and Forage Science, College of Animal Sciences and Technology, Nanjing Agricultural University

Ishiwaka, Reiko

Collaborative Research Scientist, Faculty of Agriculture, Kyushu University

Tanoue, Jun

Laboratory of Animal Feed Science, Graduate School of Bioresource and Bioenvironmental Sciences, Kyushu University

他

https://doi.org/10.5109/16117

出版情報：九州大学大学院農学研究院紀要. 54 (2)，pp. 365-367，2009-10-29. Faculty of Agriculture, Kyushu University

バージョン :

権利関係 : 


\title{
A Preliminary Investigation into Dynamics of Lotka-Volterra Equation
}

\author{
Masataka SHIMOJO*, Tao SHAO, Reiko ISHIWAKA ${ }^{1}$, Jun TANOUE ${ }^{2}$, \\ Hidetoshi KAKIHARA ${ }^{2}$, Chiemi SATA ${ }^{2}$, Hayato FUKUDOME ${ }^{2}$, \\ Yoki ASANO ${ }^{3}$, Yutaka NAKANO ${ }^{4}$, Manabu TOBISA ${ }^{5}$ \\ and Yasuhisa MASUDA ${ }^{6}$
}

\begin{abstract}
Laboratory of Animal Feed Science, Division of Animal Science, Department of Animal and Marine Bioresource Sciences, Faculty of Agriculture, Kyushu University, Fukuoka 812-8581, Japan and Department of Grassland and

Forage Science, College of Animal Sciences and Technology, Nanjing Agricultural University, Weigang 1, Nanjing 210095, the People's Republic of China (Received April 30, 2009 and accepted July 13, 2009)
\end{abstract}

\begin{abstract}
This study was conducted to investigate dynamics of Lotka-Volterra equation by introducing the second derivative for change acceleration in the number of predators and prey. Lotka-Volterra equation gives a simple model to the analysis of predator-prey relationships. The results obtained were as follows. Introducing the second derivative into Lotka-Volterra equation gave the square of change rate of the number of predators and that of prey. Since the square of change rate gave positive value, the following two inequalities were given. (1) Change acceleration of the number of prey per prey was higher than the product of $-\beta$ and change rate of the number of predators. (2) Change acceleration of the number of predators per predator was higher than the product of $\delta$ and change rate of the number of prey. These two might be related to the change in the number of predators and prey. It was suggested from the present study that investigating dynamics of Lotka-Volterra equation gave inequalities showing some change aspects of predator-prey relationships.
\end{abstract}

\section{INTRODUCTION}

Animals require feeds in order to live and grow. There is a predator-prey relationship in the world of wild animals (Iwasa, 2008), and the life of predators depends greatly on the presence of prey. The presence of a large number of prey increases the number of predators and this leads to the decrease in the number of prey, resulting in the decrease in the number of predators. This is followed by the increase in the number of prey again, if there is a large decrease in the number of predators. Therefore, there are oscillations in the number of predators and prey (Iwasa, 2008). It is known that Lotka-Volterra equation gives a simple model to the analysis of these oscillations in predator-prey relationships (Iwasa, 2008). It is of interest to study dynamics of predator-prey relationships, and this may be related to change acceleration in the number of them.

The present study was designed to investigate dynamics of Lotka-Volterra equation by introducing the second derivative for change acceleration in the number of predators and prey.

Collaborative Research Scientist, Faculty of Agriculture, Kyushu University

${ }^{2}$ Laboratory of Animal Feed Science, Graduate School of Bioresource and Bioenvironmental Sciences, Kyushu University

Employed Research Scientist, Miyazaki University, Miyazaki 889-2192, Japan

${ }^{4}$ University Farm, Faculty of Agriculture, Kyushu University

${ }^{5}$ Faculty of Agriculture, Miyazaki University, Miyazaki 889-2192, Japan

${ }^{6}$ Emeritus Professor of Kyushu University

* Corresponding author (E-mail: mshimojo@agr.kyushu-u.ac.jp)
DYNAMICS OF LOTOKA-VOLTERRA EQUATION SUGGESTED BY CHANGE ACCELERATION IN THE NUMBER OF PREDATORS AND PREY

\section{(A) Introducing the second derivative into Lotka-} Volterra equation

Lotka-Volterra equation is given by two differential equations as follows (Iwasa, 2008),

$$
\begin{aligned}
& \frac{d x}{d t}=\alpha \cdot x-\beta \cdot x \cdot y, \\
& \frac{d y}{d t}=-\gamma \cdot y+\delta \cdot y \cdot x .
\end{aligned}
$$

where $x=$ the number of prey, $y=$ the number of predators, $\alpha=$ parameter related to increase $(\alpha>0), \beta=$ parameter related to decrease $(\beta>0), \gamma=$ parameter related to decrease $(\gamma>0), \delta=$ parameter related to increase $(\delta>0)$.

Equation (1) describes the change rate in the number of prey, and equation (2) describes that of predator.

The differentiation of equation (1), namely the second derivative, gives

$$
\begin{aligned}
\frac{d^{2} x}{d t^{2}} & =\alpha \cdot \frac{d x}{d t}-\beta \cdot \frac{d x}{d t} \cdot y-\beta \cdot x \cdot \frac{d y}{d t} \\
& =\frac{d x}{d t} \cdot \frac{(\alpha \cdot x-\beta \cdot x \cdot y)}{x}-\beta \cdot x \cdot \frac{d y}{d t} \\
& =\frac{1}{x} \cdot\left(\frac{d x}{d t}\right)^{2}-\beta \cdot x \cdot \frac{d y}{d t} .
\end{aligned}
$$

Thus, 
$\left(\frac{d x}{d t}\right)^{2}=x \cdot \frac{d^{2} x}{d t^{2}}+\beta \cdot x^{2} \cdot \frac{d y}{d t}$.

Likewise, the differentiation of equation (2) gives

$$
\begin{aligned}
& \frac{d^{2} y}{d t^{2}}=-\gamma \cdot \frac{d y}{d t}+\delta \cdot \frac{d y}{d t} \cdot x+\delta \cdot y \cdot \frac{d x}{d t} \\
&=\frac{d y}{d t} \cdot \frac{(-\gamma \cdot y+\delta \cdot y \cdot x)}{y}+\delta \cdot y \cdot \frac{d x}{d t} \\
&=\frac{1}{y} \cdot\left(\frac{d y}{d t}\right)^{2}+\delta \cdot y \cdot \frac{d x}{d t} .
\end{aligned}
$$

Thus,

$$
\left(\frac{d y}{d t}\right)^{2}=y \cdot \frac{d^{2} y}{d t^{2}}-\delta \cdot y^{2} \cdot \frac{d x}{d t} .
$$

The relationship between the left- hand side and the first term in the right-hand side in each of equations (4) and (6) comes from the same relationship in each of equations (1) and (2) for Lotka-Volterra equation. This is caused by the property of exponential functions with base $e$. The same phenomenon is also observed in basic growth mechanics (Shimojo, 2007; Shimojo et al., 2006, 2007a, 2007b, 2008, 2009a, 2009b, 2009c, 2009d). Thus,

$$
W=W_{0} \cdot \exp (r \cdot t)
$$

where $W=$ weight, $t=$ time, $W_{\mathbf{0}}=W$ at $t=0, r=$ relative growth rate,

and then introducing the first and second derivatives into basic growth function (7) gives

$$
\left(\frac{d W}{d t}\right)^{2}=W \cdot \frac{d^{2} W}{d t^{2}}
$$

Shimojo (2007) and Shimojo et al. (2006, 2007b, 2008, 2009d) suggest that the form of equation (8) shows an analogy with that of Newton's equation of motion that is given as follows (Kawabe, 2006),

$$
\frac{d p}{d t}=m \cdot \frac{d^{2} r}{d t^{2}}
$$

where $p=$ momentum, $m=$ mass of an object, $r=$ position, $t=$ time.

Equations (4) and (6) also include the part showing an analogy with equation (9). However, the presence of nonlinear term in equations (4) and (6), namely the second term of the right-hand side, shows that Lotka-Volterra equation takes more complex form.

\section{(B) Inequalities derived from equations (4) and (6)}

The inequality (4-3) is derived from equation (4) according to the following procedures,

$$
\begin{aligned}
& \left(\frac{d x}{d t}\right)^{2}=x \cdot \frac{d^{2} x}{d t^{2}}+\beta \cdot x^{2} \cdot \frac{d y}{d t} . \\
& \left(\frac{d x}{d t}\right)^{2}>0, \\
& x \cdot \frac{d^{2} x}{d t^{2}}+\beta \cdot x^{2} \cdot \frac{d y}{d t}>0,
\end{aligned}
$$

therefore,

$$
\frac{1}{x} \cdot \frac{d^{2} x}{d t^{2}}>-\beta \cdot \frac{d y}{d t}
$$

Inequality (4-3) shows that change acceleration of the number of prey per prey is higher than the product of $-\beta$ and change rate of the number of predators.

Likewise, the inequality (6-3) is derived from equation (6),

$$
\begin{aligned}
& \left(\frac{d y}{d t}\right)^{2}=y \cdot \frac{d^{2} y}{d t^{2}}-\delta \cdot y^{2} \cdot \frac{d x}{d t} \\
& \left(\frac{d y}{d t}\right)^{2}>0 \\
& y \cdot \frac{d^{2} y}{d t^{2}}-\delta \cdot y^{2} \cdot \frac{d x}{d t}>0,
\end{aligned}
$$

therefore,

$$
\frac{1}{y} \cdot \frac{d^{2} y}{d t^{2}}>\delta \cdot \frac{d x}{d t}
$$

Inequality (6-3) shows that change acceleration of the number of predators per predator is higher than the product of $\delta$ and change rate of the number of prey.

\section{(C) Inequalities in Lotka-Volterra equation}

The outline of what Loka-Volterra equation shows is as follows. (1) If there are not predators, then the prey shows an exponential increase. (2) If predators are present, then the prey shows a decrease in number. (3) If there is a decrease in the number of prey, then predators show a decrease in number. (4) If the number of predators decreases greatly, then prey shows an increase. (5) If the prey is not present, then predators show an exponential decrease.

The present preliminary investigation into inequalities that are derived from dynamics of Loka-Volterra equation shows the following two. (6) Change acceleration of the number of prey per prey is higher than the 
product of $-\beta$ and change rate of the number of predators. (7) Change acceleration of the number of predators per predator is higher than the product of $\delta$ and change rate of the number of prey. Phenomena (6) and (7) suggested in the present study may be related to phenomena $(1) \sim(5)$.

\section{(D) Conclusions}

It is suggested from the present study that investigating dynamics of Lotka-Volterra equation gives inequalities showing some change aspects of predator-prey relationships.

\section{ACKNOWLEDGEMENTS}

We wish to thank Professor Dr Tetsuji Kawabe, Faculty of Design at Kyushu University, who kindly showed us the significance of Lotka-Volterra equation and responded to our inquiries.

\section{REFERENCES}

Iwasa, Y. 2008 An Introduction to Mathematical Biology. Kyoritsu Shuppan Co., Ltd., Tokyo (written in Japanese)

Kawabe, T. 2006 Standard Mechanics. Shokabo Publishing Co., Ltd., Tokyo. (written in Japanese)

Shimojo, M., K. Ikeda, Y. Asano, R. Ishiwaka, H. Sato, Y. Nakano, M. Tobisa, N. Ohba, M. Eguchi and Y. Masuda 2006 Introducing viewpoints of mechanics into basic growth analysis - (I) Three aspects of growth mechanics compared with three laws of motion -. J. Fac. Agr., Kyushu Univ., 51: $285-287$

Shimojo, M. 2007 Introducing viewpoints of mechanics into basic growth analysis - (IV) Hypothetic aspects of growth mechanics compared with momentum, impulse and kinetic energy in motion -. J. Fac. Agr., Kyushu Univ., 52: 73-75

Shimojo, M., K. Ikeda, Y. Asano, R. Ishiwaka, H. Sato, Y. Nakano, M. Tobisa, N. Ohba, M. Eguchi and Y. Masuda 2007a Introducing viewpoints of mechanics into basic growth analysis - (III) Applying growth force and leaf-light complex to production and digestion analyses of forages -. J. Fac. Agr., Kyushu Univ., 52: 69-72

Shimojo, M., Y. Asano, R. Ishiwaka, H. Sato, Y. Nakano, M. Tobisa, N. Ohba, M. Eguchi and Y. Masuda 2007b Introducing viewpoints of mechanics into basic growth analysis - (VI) Some solutions to a simple differential equation associated with growth mechanics -. J. Fac. Agr., Kyushu Univ., 52: 361-365

Shimojo, M., T. Shao and Y. Masuda 2008 Introducing viewpoints of mechanics into basic growth analysis - (VII) Mathematical properties of basic growth mechanics in ruminant -. J. Fac. Agr., Kyushu Univ., 53: 453-458

Shimojo, M., M. F. Youssef and Y. Masuda 2009a Introducing viewpoints of mechanics into basic growth analysis - (VIII) Applying basic growth mechanics to ruminants, forages and related problems -. J. Fac. Agr., Kyushu Univ., 54: 133-136

Shimojo, M., Y. Asano, R. Ishiwaka, Y. Nakano, M. Tobisa, N. Ohba M. Eguchi and Y. Masuda 2009b Introducing viewpoints of mechanics into basic growth analysis - (IX) Hypothetic quasi-four-dimensional growth mechanics -. J. Fac. Agr., Kyushu Univ., 54: 137-139

Shimojo, M., T. Shao, J. Tanoue, H. Kakihara, C. Sata, H. Fukudome, R. Ishiwaka, Y. Asano, Y. Nakano, M. Tobisa and Y. Masuda 2009c Introducing viewpoints of mechanics into basic growth analysis - (XI) Negative weight problem in basic growth functions and its hypothetic avoidance by sign reversal of relative growth rate, space inversion and time reversal -. $J$. Fac. Agr., Kyushu Univ., 54: 353-355

Shimojo, M., T. Shao, S. Ishimatsu, J. Tanoue, H. Kakihara, C. Sata, H. Fukudome, R. Ishiwaka, Y. Asano, Y. Nakano, M. Tobisa and Y. Masuda 2009d Introducing viewpoints of mechanics into basic growth analysis - (XIII) Comparing growth mechanics between logistic functions and basic growth functions -. J. Fac. Agr., Kyushu Univ., 54: 361363 